\section{FIRST RECORD OF GENUS SILER SIMON, 1889 (ARANEAE: SALTICIDAE) FROM INDIA}

\section{Siddharth Kulkarni ${ }^{1} \&$ Sunny Joseph ${ }^{2}$}

${ }^{1}$ Biome Conservation Foundation, 18, Silver Moon Apts.,1/2A/2, Bavdhan Kh., Pune, Maharashtra 411021, India

${ }^{2}$ Kidangeth, Chilavannur Road, South Kadavanthra, Cochin, Kerala 682020, India

${ }^{1}$ sskspider@gmail.com (corresponding author), ${ }^{2}$ sunnyjosef@gmail.com

The oriental genus Siler Simon, 1889, which was erected with the description of female Siler cupreus Simon, 1889 from Japan, comprises globally of nine valid species (World Spider Catalog 2015), (Table 1). Of these, Siler semiglaucus (Simon, 1901) is the most widely distributed species and has been geographically recorded nearest to India.

Specimens collected from Chilavannur $(9.965 \mathrm{~N}$ \& 76.306E) were preserved in $70 \%$ alcohol and examined with Brunel IMXZ stereozoom microscope and imaged using Canon $1200 D^{\mathrm{TM}}$ mounted camera. The examined specimens are deposited at Bombay Natural History Society (BNHS), Mumbai with registration numbers as given in the material examined below. Species identification was confirmed by comparing with Prószyński (1985) and matched with the species' lectotype (J. Prószyński pers. comm. 11 February 2015).

\section{Siler semiglaucus (Simon, 1901) (Images 1-4)}

Material examined: 3 males (BNHS Sp.182-184), February 2015, Chilavannur, Cochin, Kerala, coll. Sunny Joseph; 1 female (BNHS Sp. 185), February 2015, Chilavannur, Cochin, Kerala, coll. Sunny Joseph.

Body colour pattern similar in male and female. Dorsum coloured with iridescent scales when live (Image $1)$, lose shine in alcohol, ventrally yellowish. Carapace pattern comprising red between dorsal and lateral blue stripe. Femora and patella I brown, rest yellow with longitudinal black stripes. Abdomen densely covered with two blue spots embedded in red patch, distally grey. Cymbium longer than palpal tibia, embolus curved with pointed tip (Image 2a); tibial apophysis pointed, arising 45 degrees (Image 2b). Female epigynum ventrally with common transverse oval opening, anterior margin partially enclosing copulatory opening and posterior margin bent inwards (Image 3a). In dorsal view, copulatory duct broadened inwards, broadest before joining spherical spermatheca (Image 3b).

Discussion: This is a new record of Siler semiglaucus from India, which was previously recorded from neighbouring region of Sri Lanka. Although, this is first scientific record of the genus Siler, the images of these
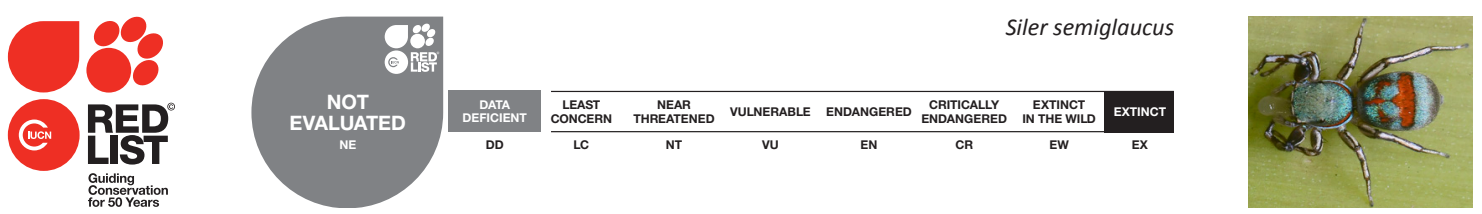

DOI: http://dx.doi.org/10.11609/JoTT.04266.7701-3 | ZooBank: urn:Isid:zoobank.org:pub:B349C69D-6EAC-47B1-9D38-8AC1AFF84A35

Editor: Anonymity requested.

Date of publication: 26 August 2015 (online \& print)

Manuscript details: Ms \# 04266 | Received 03 March 2015 | Final received 03 May 2015 | Finally accepted 14 August 2015

Citation: Kulkarni, S. \& S. Joseph (2015). First record of genus Siler Simon, 1889 (Araneae: Salticidae) from India . Journal of Threatened Taxa 7(10): 7701-7703; http://dx.doi.org/10.11609/JoTT.04150.7701-3

Copyright: @ Kulkarni \& Joseph 2015. Creative Commons Attribution 4.0 International License. JoTT allows unrestricted use of this article in any medium, reproduction and distribution by providing adequate credit to the authors and the source of publication.

Funding: Self-funded.

Competing interests: The authors declare no competing interests

Acknowledgements: SK is thankful to Thomas Vattakaven, India Biodiversity Portal for photographing Siler firstly from southern India that led to this study, Jerzy Prószyński for helpful discussions and Priyadarsanan Dharma Rajan for commenting on the ant identity. 


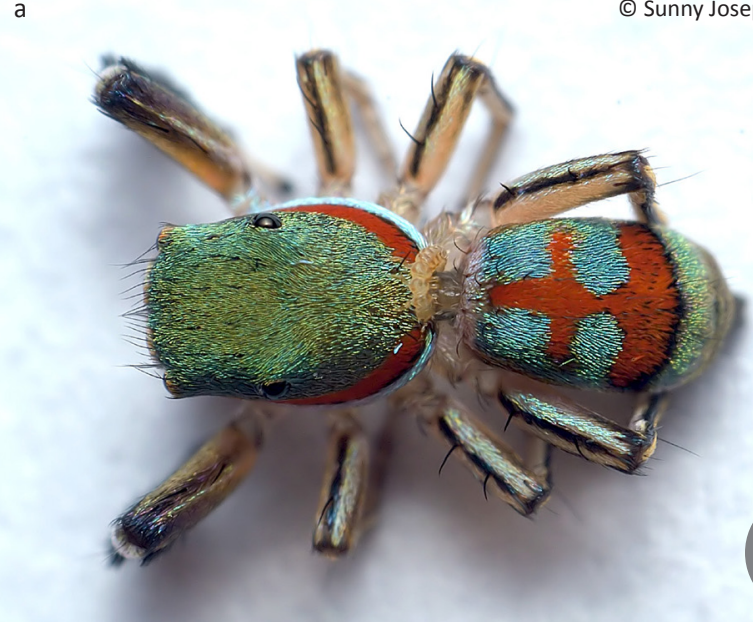

(c) Sunny Joseph

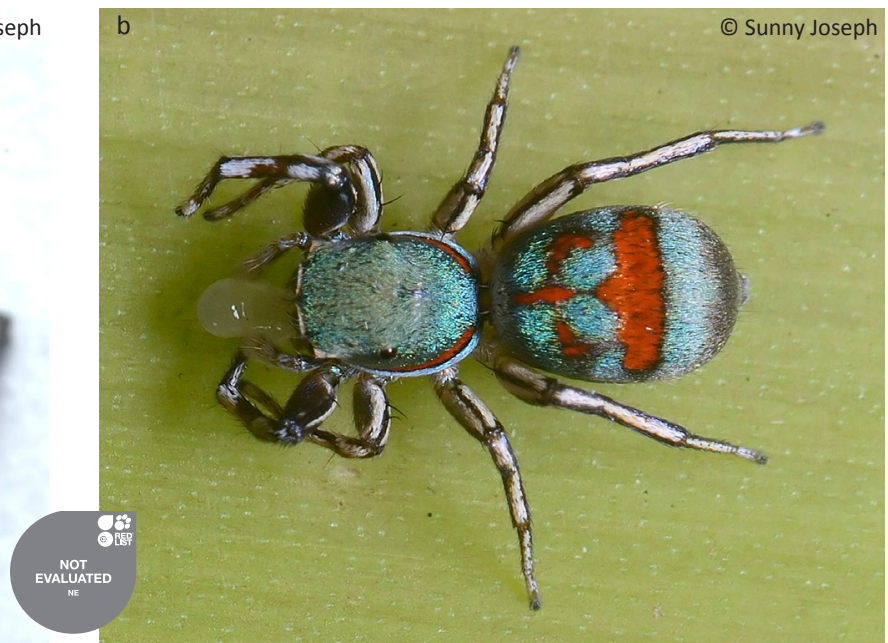

Image 1. Siler semiglaucus. a - male habitus, dorsal view; b - female habitus, dorsal view

Table 1. Distribution of Siler species

\begin{tabular}{|l|l|}
\hline Species & Known distribution \\
\hline Siler bielawskii Zabka, 1985 & China, Vietnam \\
\hline $\begin{array}{l}\text { Siler collingwoodi (O. Pickard-Cambridge, } \\
1871 \text { ) }\end{array}$ & China, Japan \\
\hline Siler cupreus Simon, 1889 & China, Korea, Taiwan, Japan \\
\hline Siler flavocinctus (Simon, 1901) & Singapore \\
\hline Siler hanoicus Prószyński, 1985 & Vietnam \\
\hline $\begin{array}{l}\text { Siler lewaense Prószyński \& Deeleman- } \\
\text { Reinhold, 2010 }\end{array}$ & Sumba \\
\hline Siler pulcher Simon, 1901 & Malaysia \\
\hline Siler semiglaucus (Simon, 1901) & Sri Lanka to Philippines \\
\hline Siler severus (Simon, 1901) & China \\
\hline
\end{tabular}

spiders from India have been on internet since 2010 (Nature Magnified 2010). It is noticeable from them, that they could be more than one species of Siler and therefore, need further study.

Nelson et al. (2004) and Jackson \& Olphen (1992) have experimentally proved Siler semiglaucus to be myrmecophagic from Philippines and Sri Lanka respectively. Jackson \& Olphen (1992) discussed preference for ants as prey by $S$. semiglaucus, however they feed upon any insect when starved for more than two weeks. During field survey, these spiders were observed to feed on Technomyrmex sp. ants (Image 4). Apart from the adults of ants, these spiders also fed upon the eggs, larvae and pupae of those ants (Image 1b).
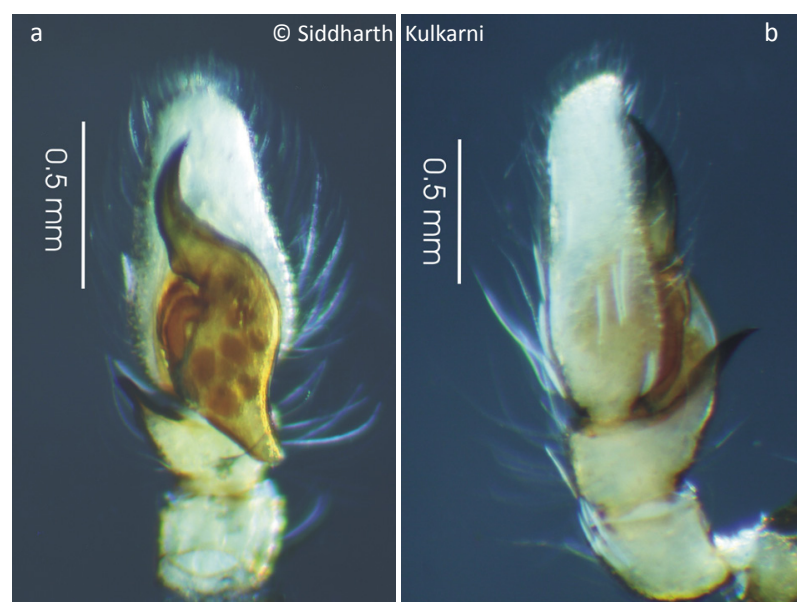

Image 2. Siler semiglaucus. a - male right palp, dorsal view; b - male right palp, ectal view

\section{References}

Nature Magnified (2010). http://www.naturemagnified.com/2010/09/ colourful-jumping-spider-siler.html. Accessed on 02 May 2015.

Nelson, X.J., R.R. Jackson, S.D. Pollard, G.B. Edwards \& A.T. Barrion (2004). Predation by ants on jumping spiders (Araneae: Salticidae) in the Philippines. New Zealand Journal of Zoology 31(1): 45-56; http://dx.doi.org/10.1080/03014223.2004.9518358

Prószyński, J. (1985). On Siler, Silerella, Cyllobelus and Natta (Araneae, Salticidae). Annales zoologici, Warszawa 39(2): 69-85

Jackson, R.R. \& A. van Olphen (1992). Prey-capturing techniques and prey preferences of Chrysilla, Natta and Siler, ant-eating jumping spiders (Araneae, Salticidae) from Kenya and Sri Lanka. Journal of Zoology, London 227: 163-170.

World Spider Catalog (2015). World Spider Catalog. Natural History Museum Bern, online at http://wsc.nmbe.ch, version 16, accessed on 01 March 2015. 

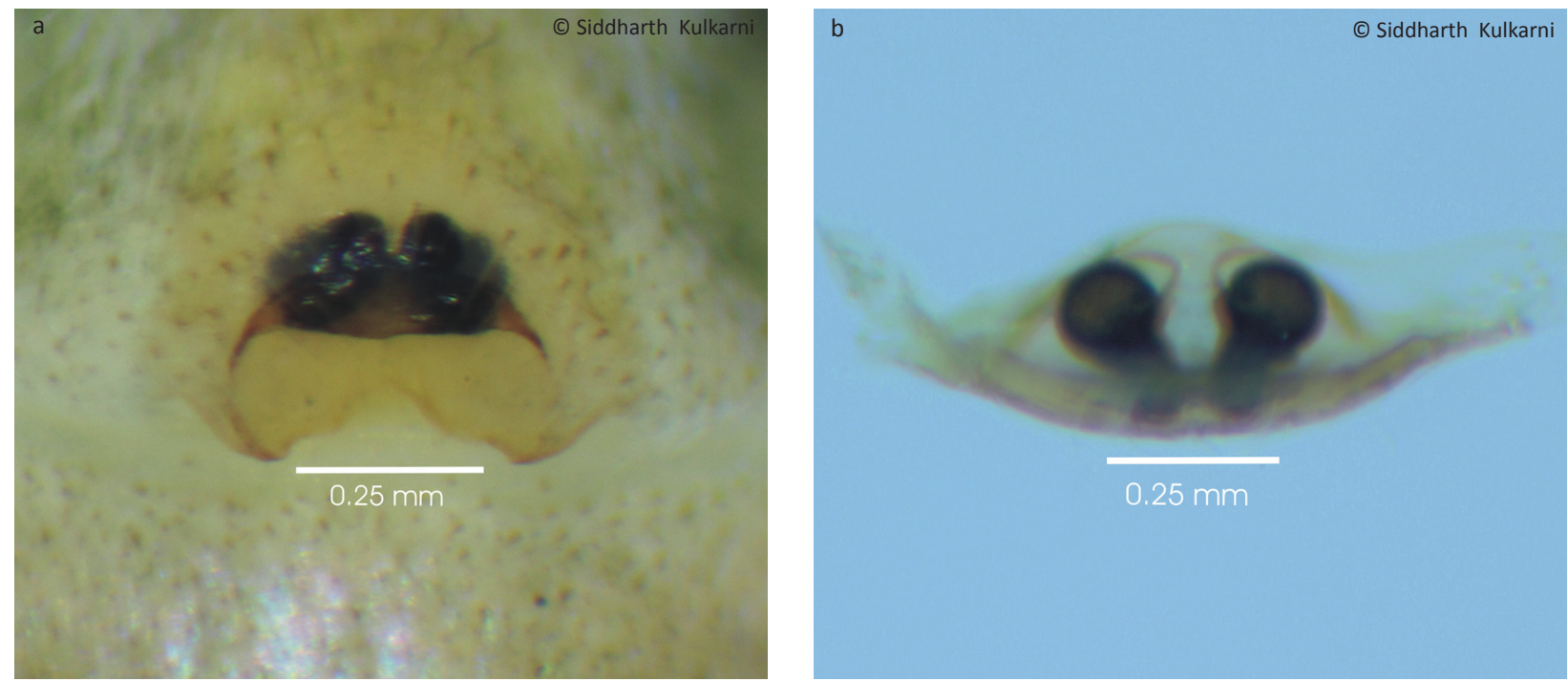

Image 3. Siler semiglaucus. a - female epigynum, ventral view; b - female epigynum, dorsal view

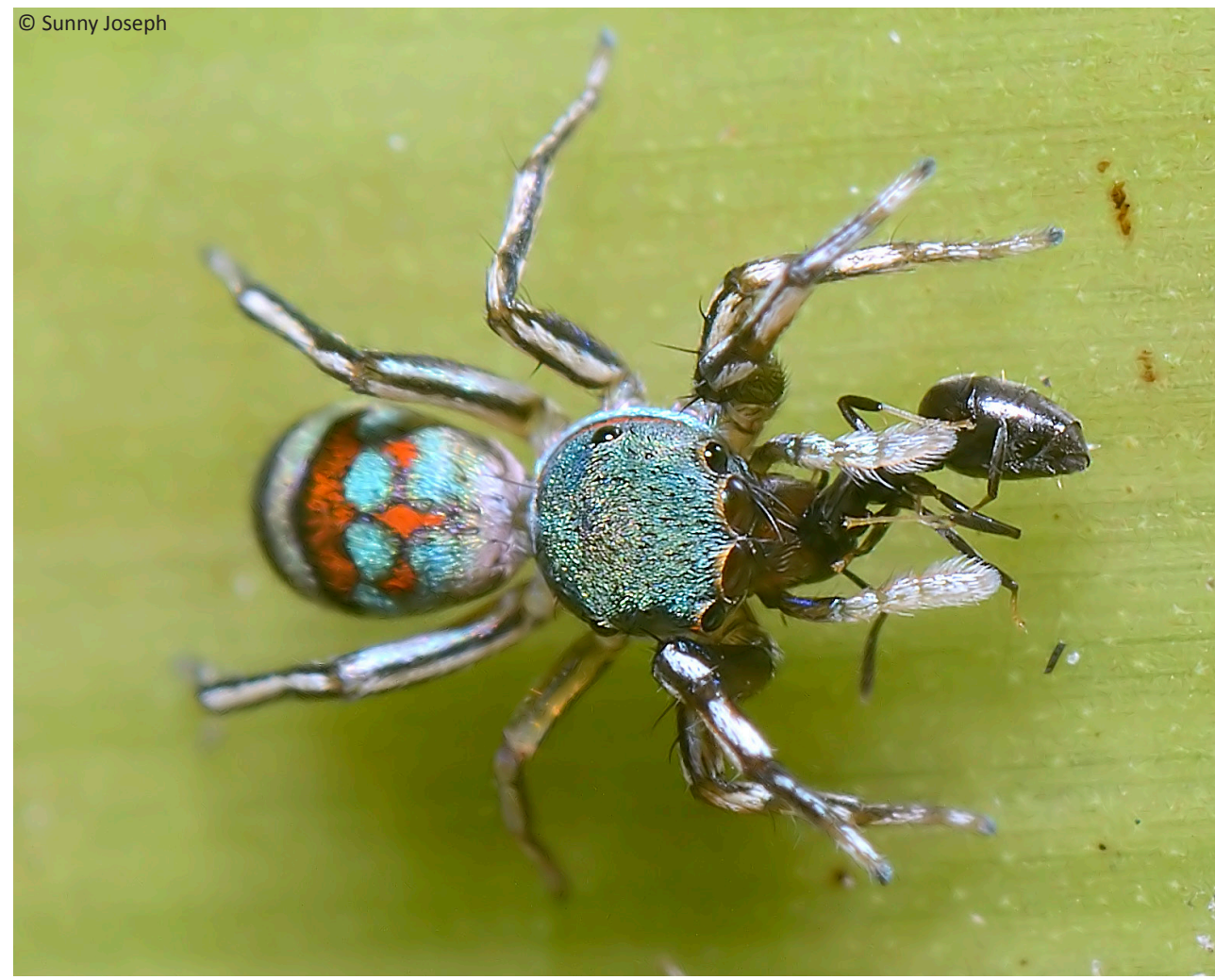

Image 4. Siler semiglaucus feeding on Technimyrmex sp. ant

Wilive

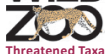

